\title{
A synthesis tree of the Copepoda: integrating phylogenetic and taxonomic data reveals multiple origins of parasitism
}

\author{
James P Bernot ${ }^{\text {Corresp., } 1,2}$, Geoffrey A Boxshall ${ }^{3}$, Keith A Crandall ${ }^{1,2}$ \\ ${ }^{1}$ Department of Invertebrate Zoology, Smithsonian National Museum of Natural History, Washington, DC, United States \\ ${ }^{2}$ Computational Biology Institute, Milken Institute School of Public Health, George Washington University, Washington, DC, United States \\ 3 Department of Life Sciences, Natural History Museum, London, United Kingdom \\ Corresponding Author: James P Bernot \\ Email address: jbernot@gwmail.gwu.edu
}

The Copepoda is a clade of pancrustaceans containing 14,485 species that are extremely varied in their morphology and lifestyle. Not only do copepods dominate marine plankton and sediment communities and make up a sizeable component of the freshwater plankton, but over 6,000 species are symbiotically associated with every major phylum of marine metazoans, mostly as parasites. Unfortunately, our understanding of copepod evolutionary relationships is relatively limited in part because of their extremely divergent morphology, sparse taxon sampling in molecular phylogenetic analyses, a reliance on only a handful of molecular markers, and little taxonomic overlap between phylogenetic studies. Here, a synthesis tree method is used to integrate published phylogenies into a more comprehensive tree of copepods by leveraging phylogenetic and taxonomic data. A literature review in this study finds fewer than 500 species of copepods have been sampled in molecular phylogenetic studies. Using the Open Tree of Life platform, those taxa that have been sampled in previous phylogenetic studies are grafted together and combined with the underlying copepod taxonomic hierarchy from the Open Tree of Life Taxonomy to make a synthesis phylogeny of all copepod species. Taxon sampling with respect to molecular phylogenetic analyses is reviewed for all orders of copepods and shows only $3 \%$ of copepod species have been sampled in phylogenetic studies. The resulting synthesis phylogeny reveals copepods have transitioned to a parasitic lifestyle on at least 14 occasions. We examine the underlying phylogenetic, taxonomic, and natural history data supporting these transitions to parasitism; review the species diversity of each parasitic clade; and identify key areas for further phylogenetic investigation. 


\section{A synthesis tree of the Copepoda: integrating phylogenetic and taxonomic data reveals}

\section{2 multiple origins of parasitism}

3

4 James P. Bernot ${ }^{1,2}$, Geoffrey A. Boxshall ${ }^{3}$, and Keith A. Crandall ${ }^{2,1}$

5

$6 \quad{ }^{1}$ Department of Invertebrate Zoology, National Museum of Natural History, Smithsonian

7 Institution, Washington, DC, USA

$8{ }^{2}$ Computational Biology Institute, Milken Institute School of Public Health, George Washington

9 University, Washington, DC, USA

$10{ }^{3}$ Department of Life Sciences, Natural History Museum, Cromwell Road, London SW7 5BD,

11 United Kingdom

12

13 Corresponding author:

14 James P. Bernot ${ }^{1,2}$

15

16 Email address: bernotj@si.edu

17

18 


\section{Abstract}

20 The Copepoda is a clade of pancrustaceans containing 14,485 species that are extremely varied

21 in their morphology and lifestyle. Not only do copepods dominate marine plankton and sediment

22 communities and make up a sizeable component of the freshwater plankton, but over 6,000

23 species are symbiotically associated with every major phylum of marine metazoans, mostly as

24 parasites. Unfortunately, our understanding of copepod evolutionary relationships is relatively

25 limited in part because of their extremely divergent morphology, sparse taxon sampling in

26 molecular phylogenetic analyses, a reliance on only a handful of molecular markers, and little

27 taxonomic overlap between phylogenetic studies. Here, a synthesis tree method is used to

28 integrate published phylogenies into a more comprehensive tree of copepods by leveraging

29 phylogenetic and taxonomic data. A literature review in this study finds fewer than 500 species

30 of copepods have been sampled in molecular phylogenetic studies. Using the Open Tree of Life

31 platform, those taxa that have been sampled in previous phylogenetic studies are grafted together

32 and combined with the underlying copepod taxonomic hierarchy from the Open Tree of Life

33 Taxonomy to make a synthesis phylogeny of all copepod species. Taxon sampling with respect

34 to molecular phylogenetic analyses is reviewed for all orders of copepods and shows only $3 \%$ of

35 copepod species have been sampled in phylogenetic studies. The resulting synthesis phylogeny

36 reveals copepods have transitioned to a parasitic lifestyle on at least 14 occasions. We examine

37 the underlying phylogenetic, taxonomic, and natural history data supporting these transitions to

38 parasitism; review the species diversity of each parasitic clade; and identify key areas for further

39 phylogenetic investigation.

40

41

Peer) reviewing PDF | (2021:06:61911:1:0:NEW 16 Jul 2021) 


\section{Introduction}

The Copepoda is a diverse, monophyletic group of crustaceans comprising 14,485 valid species (Walter and Boxshall, 2021) whose phylogenetic relationships remain poorly resolved for a number of reasons. First, copepods have extremely diverse body plans (e.g., size range 0.5 $\mathrm{mm}-300 \mathrm{~mm}$; 0 to 11 pairs of appendages; segmented or lacking external segmentation) and assessing homology across these disparate forms is challenging (e.g., Fig. 1) (Huys and Boxshall, 1991; Boxshall and Halsey, 2004). This is particularly true for the over 5,000 species of parasitic copepods, many of which have reduced or secondarily lost structures traditionally used in copepod classification (i.e., setal elements, segmentation, and entire appendages) (Kabata, 1979; Huys and Boxshall, 1991; Boxshall and Halsey, 2004). copepod phylogeny. Many copepods were historically preserved in formalin, which has limited the availability of specimens for molecular analysis. There is also a limited assortment of molecular markers available for copepods. The majority of molecular phylogenetic studies of copepods are single gene studies using $18 \mathrm{~S}$ or $\mathrm{CO} 1$, and in the best cases, two to four other markers (Table 1). Given that copepods are estimated to have diverged 375-450 million years ago (mya) (Schwentner et al., 2017), it is challenging to reconstruct both deep and shallow levels of the phylogeny with a small number of relatively short markers. Moreover, the most widely used marker in copepod phylogenetics is $18 \mathrm{~S}$ and it contains large indels in a number of taxa which can make alignment and phylogenetic reconstruction more challenging (Huys et al., 2012;

63 Cornils and Blanco-Bercial, 2013; Wu et al., 2016). In addition, few copepod species have sequence data available in NCBI (approximately 1,400 of 14,485 species) and many of the NCBI 
65 sequences are not identified to species level (e.g., Copepod sp. 142, Cyclopoida gen. sp., etc.)

66 (Clark et al., 2016; GenBank). Furthermore, copepod systematists have typically specialized on

67 one of five ecological groups: marine planktonic copepods, copepods inhabiting marine

68 sediments, freshwater copepods, parasitic copepods associated with fish hosts, or parasitic

69 copepods associated with invertebrate hosts (Huys and Boxshall, 1991; Boxshall and Halsey,

70 2004), and while these groups are intermingled, the focus on particular ecological groups has

71 limited the integration of copepod phylogenies into a cohesive tree of life.

Given that copepod systematics has generally been approached from a focused

73 ecological perspective, an overall view of copepod phylogeny requires an integration of these

74 independent efforts. Three main classes of methods are available for integrating phylogenies into

75 a more comprehensive tree, i.e., supertree, supermatrix, or synthesis tree (Ewers-Saucedo et al.,

76 2019). Supertree methods code phylogenies into a new matrix to be analyzed by phylogenetic

77 methods, but this requires a large number of the same taxa to be present in each study in order to

78 effectively integrate multiple phylogenies into a single tree (Bininda-Emonds, 2004). This

79 requirement would greatly reduce the number of studies incorporated, given the relatively low

80 taxonomic overlap between published copepod molecular studies. Supermatrix approaches

81 require the same characters (i.e., morphology and/or molecular loci) to be shared across studies

82 (McMahon and Sanderson, 2006), a requirement that is also problematic for available copepod

83 morphological and molecular data. Given this lack of matching data (i.e., matching taxa in

84 supertree methods and matching characters in supermatrix methods), the synthesis tree method is 85 employed here.

86 A synthesis tree grafts together published phylogenies to produce a more comprehensive

87 phylogeny including all taxa that have been sampled (Hinchliff et al., 2015; Owen et al., 2015; 
88 Redelings and Holder, 2017; Rees and Cranston, 2017; Ewers-Saucedo et al., 2019). This

89 method can also include taxa that have not been previously sampled in other phylogenetic

90 analyses by incorporating taxonomic information using the Open Tree of Life Taxonomy (OTT)

91 (Hinchliff et al., 2015; Redelings and Holder, 2017; Reese and Cranston, 2017). This works by

92 taking advantage of the tree-like properties of the Linnaean classification system; each

93 taxonomic category is a polytomy within each higher taxonomic category such that all species

94 are a polytomy within a genus, all genera are a polytomy within a family, and so on throughout

95 the taxonomic hierarchy. Given that taxonomists have strived to establish monophyletic taxa, the

96 taxonomic hierarchy is a useful null hypothesis to incorporate taxa that have never been sampled

97 in a phylogenetic analysis. This approach has the additional benefits of highlighting taxa that

98 have limited phylogenetic information, being computationally fast, and easily revised with the

99 incorporation of new studies (Redelings and Holder, 2017).

100 Here we construct a synthetic phylogeny of the Copepoda using published molecular

101 phylogenies and the OTT to build a synthesis phylogeny of all known copepod species. The

102 goals of this study are to integrate published copepod molecular phylogenies in order to

103 synthesize current information on copepod phylogeny, to identify parts of the copepod tree of

104 life that require additional sampling effort, and to use the resulting phylogeny to estimate the

105 number of times copepods have evolved a parasitic lifestyle. Improving our understanding of

106 copepod evolution is of key interest because copepods are an excellent system for studying the

107 evolution of parasitism: they have evolved to be parasitic multiple times, have an exceptionally

108 broad host range spanning 14 phyla of metazoans, and exhibit extreme morphological diversity

109 (e.g., Fig. 1) (Boxshall and Halsey, 2004). 


\section{Materials and Methods}

112 A literature review for molecular phylogenies of copepods was conducted using Google

113 Scholar and the follow search term <"copepod AROUND(5) phylogeny" molecular $>$. As of June

11401,2021 this produced 178 search results, which were screened individually for copepod

115 phylogenies. Despite containing the search terms, the majority of search results did not contain

116 original molecular phylogenies of copepods. Other relevant literature was added manually, such

117 as phylogenetic studies at higher taxonomic levels above copepods that were lacking the search

118 terms. Of the approximately 75 results that did contain original phylogenies, the following

119 exclusion criteria were applied. If a study contained only a subset of taxa and loci that were

120 sampled in another study using comparable methods, the smaller phylogeny was excluded.

121 Studies that contained only intraspecific taxon sampling or that had low support $(<70 \%$ BS or

$122<0.95$ PP) at all interspecific nodes were excluded. Those with highly disjunct taxon sampling,

123 such as unrelated species from a particular region or habitat, were also excluded to avoid

124 sampling bias that, in the absence of more even taxon sampling, would lead to the accumulation

125 of these taxa towards the base of the synthesis tree. Phylogenies from studies that contained

126 multiple single gene phylogenies with high conflict, no combined analyses, and no objectively

127 preferred topology were also excluded to avoid subjectivity. Finally, unrooted phylogenies were

128 excluded because the synthesis tree method requires rooted trees.

129 All phylogenies were reconstructed manually in Mesquite v3.31 (Maddison and

130 Maddison, 2017) based on the published figures and imported into the Open Tree of Life. The

131 phylogenies were grafted together individually and with underlying taxonomic information (OTT

132 v3.2) (Reese and Cranston, 2017) using the propinquity pipeline (Redelings \& Holder, 2017). As

133 required by that pipeline, the studies were ranked; ranking was based on (1) density of taxon 
134 sampling of the focal clade (sparser taxon sampling and geographic vs phylogenetic scope

135 ranked lower), (2) number of loci, and (3) methodology (neighbor joining and parsimony

136 methods ranked lower than ML and BI methods). The specific phylogeny figures used from each

137 study and their relative rankings are shown in Table 1. Two phylogenies were produced using the

138 propinquity pipeline: a grafted tree of all input taxa (grafted_solutions_ottnames.tre,

139 Supplemental data S1) and a grafted tree including those taxa as well as taxonomic data for all

140 copepod species (labelled_supertree_simplified_ottnames.tre) (Supplement data S2). Ancestral

141 state reconstruction analyses were conducted on the grafted tree of all input taxa from the

142 propinquity analysis (i.e., grafted_solutions_ottnames.tre) by scoring each taxon as free-living or

143 parasitic in PAUP* (v4.0a168) (Swofford, 2003) under a parsimony reconstruction method using

144 ACCTRAN and DELTRAN. Parsimony was the only possible ancestral state reconstruction

145 method because trees produced by the propinquity pipeline do not contain branch lengths. An

146 additional parsimony ancestral state reconstruction was also carried out in PAUP* under an

147 irreversible parsimony model that did not allow for reversals from parasitic to free-living

148 (DEFTYPE=IRREV) since the evolution of parasitism has been speculated to be an irreversible

149 transition (e.g., Futuyma and Moreno 1988; Cruickshank and Paterson, 2006; Goldberg and Igic,

150 2008). The resulting phylogenies (Figs. 2, 3) were visualized using the Interactive Tree of Life

151 v3 (Letunoc \& Bork, 2016).

152 In order to categorize parasitic copepods among the many copepods associated with other

153 organisms, an operational definition of parasitism was applied to demarcate parasites along the

154 continuum of symbioses (i.e., mutualism to commensalism to parasitism). Here, we follow

155 Combes (2007) and define parasitism as an interspecific symbiotic association between two

156 organisms in which one organism (the parasite) has a nutritional dependence on the other (the 
157 host) for a prolonged period of time and has a negative impact on the fitness of the host,

158 differing from Combes (2007) only in the qualification of for a prolonged period of time to

159 ensure the association is durable and to exclude micropredators.

\section{Results}

162 Copepod phylogeny and synthesis tree

In total 26 relevant publications encompassing 31 phylogenies based on molecular data

were identified and added to the Open Tree of Life online curatorial system where they are publicly available (https://tree.opentreeoflife.org/curator/profile/jbernot/copepoda) (McTavish et al., 2015). The synthesis tree of copepods includes 15,763 terminals (Fig. 3), substantially more than the 14,485 curated copepod species documented in the World of Copepods database (Walter and Boxshall, 2021). The approximately 1,200 additional terminals come primarily from NCBI registrants that include putatively identified species (e.g., those with a "cf." designation), undescribed species (e.g., Caligus sp. 1), and environmental samples not identified to the species level (e.g., Cyclops sp. environmental sample). total, only $3 \%(365 / 14,485)$ of copepod species have been examined in a molecular phylogenetic context. The phylogeny resulting from grafting together the published phylogenies is shown in

175 Figure 2. Some copepod taxa have been sampled in greater detail, while others have been largely unexplored in terms of their phylogenetic relationships. The most well-sampled order of copepods is the Calanoida. While only $6 \%(173 / 2,709)$ of calanoid species have been included in molecular phylogenetic analyses, the limited species-level taxon sampling has spanned 70\%

179 (31/44) of calanoid families. The three orders Siphonostomatoida, Harpacticoida, and 
180 Cyclopoida encompass $80 \%(11,449 / 14,485)$ of copepod species, but few species in each of

181 these orders have ever been studied in a molecular phylogenetic context. In the Cyclopoida, only

$1823 \%(141 / 4,500)$ of species spanning 39\% (40/103) of families have been included in a molecular

183 phylogenetic analysis. The Harpacticoida and Siphonostomatoida are the most poorly sampled

184 with $<1 \%(29 / 4,687)$ of harpacticoid species and $17 \%(14 / 79)$ of families sampled and $1 \%$

$185(23 / 2,262)$ of siphonostomatoid species and $26 \%(15 / 58)$ of families of sampled.

186

187 Transitions to parasitism

188 Despite the limited taxon sampling of copepods in molecular phylogenetic studies, we

189 identify multiple clades of parasitic copepods. Evidence supporting each parasitic clade is

190 presented in one of three ways: direct phylogenetic support, indirect phylogenetic support, and

191 taxonomic support based on morphology. Direct phylogenetic support consists of cases in which

192 the parasitic taxon has been sequenced and molecular phylogenetic analysis shows it is distinct

193 from all other parasitic clades in the ancestral state reconstruction analysis (solid red branches in

194 Fig. 2). We refer to other clades as having indirect phylogenetic support (dotted red branches in

195 Fig. 2). In these cases, a taxon that contains both free-living and parasitic species was included in

196 a molecular phylogenetic analysis, but the parasitic species themselves have not been sampled.

197 Finally, we identify a number of transitions to parasitism in taxa that have not been sampled in

198 molecular phylogenetic analyses, but that have taxonomic support based on morphology

199 suggesting their independence from all other parasitic clades.

200 There is direct phylogenetic support for seven transitions to parasitism comprising the

201 following clades: Alteuthellopsis Lang, 1948, Ameiridae Boeck, 1865; Lernaeidae Cobbold,

202 1879; Notodelphyidae Dana, 1853 (plus related families of tunicate parasites); the poecilostome 
203 cyclopoids previously classified as the "Poecilostomatoida"; a single origin in

204 Siphonostomatoida + Monstrilloida; and Thaumatopsyllidae Sars, 1913 (solid red branches in

205 Fig. 2). The unconstrained parsimony analyses supported two reversals from parasitic to free-

206 living lifestyles (bold black branches in Fig. 2). ACCTRAN and DELTRAN parsimony analyses

207 were identical. An analysis constrained to not allow reversals from parasitism back to free-living

208 supported eight, rather than 1, transitions to parasitism in the poecilostome cyclopoids (red

209 arrowheads in Fig. 2). Many parasitic copepods remain to be sampled in phylogenetic analyses.

210 There were also some indirect phylogenetic data supporting four additional parasitic

211 clades (dotted red branches in Fig. 2). These three instances comprise the harpacticoid taxa:

212 Aglaogastes cnidicus (Humes, 1981) Huys, 2016; Canuellidae Lang, 1940, Thalestridae Claus,

213 1862, and the cyclopoid genus Eucyclops Claus, 1893, all of which represent independent clades

214 in this analysis, but for which only free-living species were sampled in published molecular

215 phylogenetic analyses. Assuming the familial and generic placement of the parasitic members of

216 these taxa is correct, the dotted lines in Figure 2 indicate four additional transitions to parasitism

217 in the copepod phylogeny.

218 Taxonomic data for all copepod species based on morphology adds an additional data

219 layer to this study and provides support for three more transitions to parasitism. The harpacticoid 220 taxa Balaenophilus Aurivillius, 1879, Cholidyinae Boxshall, 1979, and Laophontidae Scott, 1904

221 each contain parasitic species, but none of these taxa have been sampled in a molecular

222 phylogenetic analysis. If the current taxonomic hierarchy is correct such that these three taxa are

223 indeed distinct from the 11 parasitic clades mentioned above, there are at least 14 independent

224 clades of parasites within the Copepoda (Fig. 3). By including taxonomic information for all

225 copepod species, we show the diversity of the parasitic clades varies from a single species in 
226 three cases to two instances of over 2,000 parasitic species in the large siphonostomatoid and

227 poecilostome clades (Table 3, Fig. 3).

228

229 Discussion

230 Copepod phylogeny and synthesis tree

231 The phylogenetic sampling of copepods has not been distributed evenly across the

232 copepod tree. The copepod orders with the greatest diversity, in terms of species richness,

233 morphological variation, and lifestyles, remain the most poorly sampled, that is, the Cyclopoida,

234 Harpacticoida, and Siphonostomatoida. These three orders encompass nearly all parasitic

235 copepod species except for the 173 parasitic species in the Monstrilloida, which is thought to be

236 closely allied with, or even nested within, the Siphonostomatoida (see Huys et al. [2007]).

To better understand copepod evolution, it is necessary to sample many higher taxa (e.g., copepod orders and families) that have not yet been included in molecular phylogenetic analyses.

239 This is particularly true for the four orders Gelyelloida, Misophrioida, Mormonilloida, and

240 Platycopioida that have never been sampled in molecular phylogenetic studies relative to the

241 other copepod orders. In addition, the Cyclopoida, Harpaticoida, and Siphonostomatoida, which

242 comprise $>80 \%$ of copepod diversity, require greater sampling effort; only $40 / 103,14 / 79$, and

243 15/58 families, respectively, have been included in phylogenetic studies. Furthermore,

244 phylogenetic relationships of the Cyclopoida and Harpacticoida are key to our understanding of

245 the evolution of parasitism, and, particularly in the cyclopoids, morphological evolution and the 246 colonization of freshwater.

A notable artefact of the synthesis method here is the placement of Cyclopicina in a basal

248 polytomy comprising the Siphonostomatoida, Harpacticoida, and Cyclopoida (Fig. 2). Khodami 
249 et al. (2019) showed this genus to be sister to all other cyclopoids they sampled, but because this

250 genus was also sampled in the phylogeny of Huys et al. (2006) that sampled only cyclopoids and

251 siphonostomatoids, the synthesis method used here placed the Cyclopicina in a more basal

252 position due to the differing positions of this taxon in these two studies. This apparent conflict is

253 due primarily to nonoverlapping taxa in these studies rather than conflicting phylogenetic signal.

254 This is an artefact of the synthesis method; in reality, the placement of the Cyclopicina should be

255 at the base of the Cyclopoida. Greater overlap in taxon sampling across phylogenetic studies will

256 reduce this issue in future synthesis phylogenies.

257 A number of taxonomic issues remain to be addressed in the Copepoda. Comparing

258 phylogenetic and taxonomic hypotheses here shows that four orders and many families have

259 uncertain placement or are polyphyletic. Both of these issues lead to the accumulation of these

260 taxa towards the base of the copepod synthesis tree. This is because taxa that are included in a

261 polyphyletic taxon that have not themselves been sampled in a phylogenetic study (i.e., that do

262 not have corresponding phylogenetic information) can only be placed at the next higher

263 taxonomic rank in the current synthesis tree methodology. This is evident in the Harpacticoida

264 (Fig. 3) where a large basal polytomy corresponds to the majority of harpacticoid families, which

265 have yet to be sampled in a molecular phylogenetic study. Likewise, since the relationships of

266 the Gelyelloida, Misophrioida, and Mormonilloida relative to the other copepod orders have not

267 been examined in molecular phylogenetic studies, these three orders are part of a basal polytomy

268 in the superorder Podoplea. A number of cyclopoid families of uncertain placement, as well as

269 genera from podoplean families that were found to be paraphyletic also accumulated at the base

270 of the Podoplea (gray branches in Fig. 3). These are artefacts of the synthesis tree method. While

271 Khodami et al. (2019) established suborders for most cyclopoid taxa, this revised taxonomy, 
272 already adopted by WoRMS (Walter and Boxshall, 2021), has not yet been incorporated into the

273 Open Tree of Life Taxonomy (OTT). Once this taxonomic revision is incorporated into the OTT,

274 the orphaned cyclopoid families will form a polytomy at the base of the Cyclopoida rather than

275 the Podoplea. The incorporation of additional phylogenetic data into the copepod synthesis tree

276 for taxa not previously sampled (e.g., many of the cyclopoid, harpacticoid, and siphonostomatoid

277 families) will further resolve basal polytomies in the synthesis phylogeny and lead to a more

278 bifurcated synthesis tree.

279

280

\section{Transitions to parasitism}

Despite the taxon sampling limitations of copepods in molecular phylogenetic analyses,

282 the synthetic phylogeny here provides insights into copepod phylogeny and evolution,

283 particularly the multiple origins of a parasitic lifestyle among copepods. Mapping parasitic taxa

284 documented in the literature onto the synthetic phylogeny reveals parasitism has evolved in the

285 Copepoda at least 14 times (Fig 3). There are direct phylogenetic data supporting at least seven

286 independent transitions to parasitism (solid red branches in Fig. 2). Current data suggest a single

287 transition to parasitism appears to have given rise to the wholly parasitic order

288 Siphonostomatoida with the parasitic order Monstrilloida nested within it. Members of these

289 orders are obviously parasitic with negative effects on their hosts, which range from sponges to

290 fish, and include a number of economically important parasites in aquaculture (Johnson et al.,

291 2004).

292 Within the Cyclopoida there is direct phylogenetic support for four clades of parasites

293 and indirect support for a fifth clade. The clades with direct support are as follows. The largest is

294 a clade of more than 2,000 species of poecilostome copepods (Walter and Boxshall, 2021), 
295 nested within the suborder Ergasilida, whose hosts span nearly all major groups of marine

296 metazoans including fish. All but a few species are obviously parasitic, and those that are not are

297 often associated with gelatinous zooplankton (Heron, 1973; Gasca et al., 2007). Next is the

298 Notodelphyidae, comprising a group of closely related families of parasites (some are arguably

299 commensals) of solitary and colonial ascidians (Walter and Boxshall, 2021). Morphological

300 phylogenetic analysis by Ho (1994) separated the ascidicolid taxa from the Notodelphyidae +

301 Archinotodelphyidae but we have conservatively counted this as a single transition

302 encompassing the tunicate parasitizing copepods because the ascidicolid taxa have not been

303 examined in molecular phylogenetic analyses. The third clade is the Lernaeidae, an exclusively

304 parasitic family of mostly mesoparasites on freshwater fishes (Walter and Boxshall, 2021). The

305 Ozmanidae, which is associated with freshwater snails, likely belongs to this same clade (Ho,

306 1994). The fourth clade with direct support is the Thaumatopsyllidae, a unique family composed

307 of five species that, as nauplii, are endoparasites in the stomach of brittle stars (Boxshall and

308 Halsey, 2004; Khodami et al., 2019; Walter and Boxshall, 2021). The only cyclopoid clade with

309 indirect phylogenetic support is Eucyclops bathanalicola, the lone parasitic member of

310 Eucyclops. Evidence of its parasitic lifestyle comes from its location in the mantle cavity of its

311 snail host and its highly modified morphology: it attaches with modified, clawed maxillules and

312 maxillae, and its reduced maxillipeds, which are used for feeding in free-living Eucylops but are

313 vestigial lobes in this species (Boxshall and Strong, 2006).

314 Interestingly, two small clades of free-living copepods (the Oncaeidae and a second clade

315 consisting of Sapphirinidae + Corycaeidae + Pachos $)$ are nested within the large poecilostome

316 clade in the phylogeny of Khodami et al. (2019) and thus the synthesis phylogeny here. Strictly

317 interpreting this topology, either the single transition to parasitism for the entire clade of 
318 poecilostome cyclopoids includes two reversals to free-living lifestyles (bold black branches in

319 Fig. 2), or there are eight independent transitions to parasitism (red arrowheads in Fig. 2). Both

320 ACCTRAN and DELTRAN parsimony-based ancestral state reconstructions predicted reversals

321 from parasitic to free-living in this phylogeny. While the evolution of parasitism has been

322 considered an irreversible transition (e.g., Futuyma and Moreno 1988; Goldberg and Igic, 2008),

323 recent studies have called this derivative of Dollo's law into question (Cruickshank and Paterson,

324 2006; Klimov and O'Connor, 2013). The reversals from parasitism to free-living in both of these

325 instances in the Cyclopoida are similar to that observed in psoroptidian mites by Klimov and

326 O'Connor (2013). Here, the free-living taxa (i.e., Corycaeidae, Oncaeidae, Pachos, and

327 Sapphirinidae), though planktonic, are often associated with gelatinous zooplankton (Heron and

328 Damkaer, 1978; Gasca et al., 2007) and have mouthparts adapted for surface feeding rather than

329 particle feeding (Heron, 1973; Boxshall and Halsey, 2004). Alternatively, the possibility of eight,

330 rather than one, independent evolutions of parasitism in poecilostome copepods is not

331 unprecedented given the 11 other instances across the Copepoda. Denser taxon sampling is

332 needed to more definitively evaluate transitions to parasitism in poecilostome cyclopoids since

333 only $23 / 67$ poecilostome families $(75 / 2,425$ species $)$ have been sampled in molecular

334 phylogenetic analyses.

335 Within the Harpacticoida there is direct phylogenetic support for two independent clades

336 of parasites, indirect phylogenetic support for three additional clades, and taxonomic support for

337 three more parasite clades for a total of eight parasitic harpacticoid lineages. In most of these

338 cases, the nature of the association of harpacticoids with their hosts is less obviously parasitic

339 relative to other copepods. Direct phylogenetic data support two clades of parasites, one in the

340 Ameiridae and the other in the Peltidiidae. There are a number of potentially parasitic genera in 
341 the Ameiridae including Abscondicola Fiers, 1980, Antillesia Humes, 1958, Nitokra Boeck, 1865

342 and possibly a few other genera such as Cancrincola Wilson, 1913. Since the phylogeny of the

343 Ameiridae is not well known, we conservatively counted the Ameiridae as a single transition

344 represented here by Nitokra (Fig. 2). We find convincing evidence of parasitism in N. bdellurae

345 (Liddell, 1912) and N. spinipes Boeck, 1875; other species of Nitokra associated with hosts

346 including crayfish and marine isopods may be parasitic as well. Nitokra bdellurae is an egg

347 parasite or parasitoid of the turbellid flatworms and $N$. spinipes is parasitic on medusae of

348 Aurelia where it is found in huge numbers - up to 1,030 from a single medusae by Humes (1953)

349 - in pits thought to be excavated by the copepods (Liddell, 1912; Humes, 1953, 1981). Available

350 natural history data suggest the monotypic genera Abscondicola and Antillesia are additional

351 ameirid parasites. Both utilize inland gecarcinid land crabs and given that 14 to $>250$ individuals

352 were found at $100 \%$ prevalence by Fiers (1990), it is hard to believe these morphologically

353 modified copepods do not have a negative effect on host fitness given the intensity of infection.

354 Second, there is direct phylogenetic support for parasitism in a number of copepods from the

355 Peltidiidae that are associated with invertebrates. While the exact nature of their relationship with

356 hosts is unclear in most cases, we found compelling evidence of parasitism based on intense

357 infections of corals with Alteuthellopsis corallina Humes, 1981; Humes (1981) collected

358 hundreds of these copepods per coral head. Humes (1985) suggested coral-associated copepods

359 fed on coral mucus, which would make them parasites under our definition assuming mucus

360 feeding has a negative effect on corals.

361 Indirect phylogenetic data support three additional transitions to parasitism in the

362 Harpacticoida (Fig. 2 dotted red lines). First, some species of thalestrid harpacticoids are gall-

363 forming parasites living in the thallus of seaweeds (Ho and Hong, 1988; Shimono et al., 2007; 
364 Huys, 2016) and the family Thalestridae is represented here by the free-living genus

365 Phyllothalestris. If terrestrial leaf mining and gall-forming insects are considered plant parasites,

366 then so should these copepods that operate similarly. Second, the Canuellidae is also sampled in

367 analyses here, but only a few taxa are parasitic in the otherwise free-living family. Of the

368 canuellids associated with hosts, the most likely parasite is Echinosunaristes Huys, 1995 though

369 other genera including Intersunaristes Huys, 1995 and Sunaristes Hesse, 1867 may be parasitic.

370 Huys (2016) considered Echinosunaristes to be non-parasitic detritivores, but we find its

371 predilection site (the anus of sea urchins) and morphological modifications (i.e., thinner cuticle

372 thought to be a response to its sheltered microhabitat and the reduction of oral appendages

373 [Huys, 1995]) strongly suggestive of parasitism. Evidence for parasitism is less conspicuous in

374 Intersunaristes and Sunaristes though their association with hermit crabs appears durable

375 (Humes and Ho, 1969; Hamond, 1973). Third, in the Tegastidae, there are a number of copepods

376 associated with metazoan hosts and evidence of parasitism is most compelling for Aglaogastes

377 cnidicus (Humes, 1981; Huys, 2016) given that $>1,500$ copepods and 167 copepodids of $A$.

378 cnidicus were collected on a single specimen of the hydroid Aglaophenia cupressina (Humes,

379 1981). While the Tegastidae and Peltidiidae are sister taxa in Figure 2, both families include

380 many free-living species which indicates these are likely separate transitions to parasitism within

381 each family, rather than indicative of a shared parasitic ancestor.

382 Finally, while there are no molecular phylogenetic data for the following transitions to

383 parasitism because they have never been sampled in a phylogenetic analysis, there is taxonomic

384 and morphological data supporting three additional parasitic harpacticoid clades: Balaenophilus

385 Aurivillius, 1879, the Cholidyinae (family Tisbidae), and a number of genera in the

386 Laophontidae (Fig. 3). First, three species of Balaenophilus are found in high densities on marine 
387 tetrapods (whales, sea turtles, and manatees), and while the exact nature of their association with

388 some of their hosts is unclear, the abundance of baleen keratin in their fecal pellets, at least, is

389 indicative of parasitism on whales (Badillo et al., 2007). No members of Balaenophilus have

390 been sampled in molecular phylogenetic studies, but, given that their morphology differs

391 substantially from all the other clades of parasites and includes a highly modified clawed

392 nauplius larva (Ogawa et al., 1997), this too likely represents a unique evolution of parasitism,

393 perhaps nested within the Miraciidae Dana, 1846 as suggested by Willen (2000). Second, of the

394148 species within the mostly free-living family Tisbidae, there are 14 parasites in the subfamily

395 Cholidyinae (Walter and Boxshall, 2021). All but one of these parasitic species encyst within

396 deep sea cephalopods while the remaining species, Neoscutellidium yeatmani Zwerner, 1967,

397 parasitizes Antarctic Eelpout gills (Zwerner, 1967; Huys, 2016). Other members of the Tisbidae,

398 particularly some species of Tisbe, may be facultative parasites given that they are commonly

399 found in high densities on the gills of mussels, and Humes (1954) found that dislodged copepods

400 would often return to mussel gill tissue during dissection. While none of the parasitic tisbids

401 have been sampled in molecular phylogenetic studies, these species likely represent at least one

402 independent transition to parasitism within the family Tisbidae. Third, there are a number of

403 parasitic species within the Laophontidae that are conservatively counted as a single transition to

404 parasitism here since the phylogeny of the family is poorly understood. Two species of

405 Microchelonia Brady, 1918 are undoubtedly ectoparasites of sea cucumbers and have highly

406 modified morphology including scraping mouthparts and clawed legs that are no longer usable

407 for swimming (Kim, 1991; Huys, 2016). Members of other laophontid genera are also likely

408 parasitic. All life stages of the copepod genus Mictyricola Nicholls, 1957 are regularly found in

409 high densities (35-82 per host) on the setae of burrowing crabs belonging to the genus Mictyris 
410 Latreille, 1806. They are poor swimmers and have not been found off their host, even in their

411 burrows, suggesting the relationship is obligate. Even if they only scavenge on food from the

412 host, that could fall under our definition of parasitism if it reduces the energy the host receives. A

413 similar situation occurs in Robustunguis Fiers, 1992 on xanthid crabs, which have a highly

414 modified, claw-like leg 1 presumably for attachment to host setae (Fiers, 1992). A number of

415 other laophontid genera are associated with hosts such as Hemilaophonte Jakubisiak, 1933 and

416 Paralaophonte Lang, 1944 but little is known about the nature of their relationship with their

417 hosts. While none of the parasitic laophontids have been sampled in molecular phylogenetic

418 studies, these cumulatively represent at least one transition to parasitism based on Microchelonia 419 alone.

420 There is a large range in species richness of the 14 clades of parasitic copepods (Table 3).

421 The transition to parasitism has resulted in a massive evolutionary radiation and in the

422 colonization of more than 10 host phyla on two occasions: the Siphonostomatoida +

423 Monstrilloida (2,435 species) and the peocilostome Cyclopoids (2,235 species) (Walter and

424 Boxshall, 2021). Both of these transitions occurred $>100$ mya ago, though the exact timing is

425 unclear given the limited fossils of parasitic copepods and molecular divergence time

426 estimations. Still, trace fossils of parasitic cyclopoids in echinoids are known from at least $\sim 168$

427 mya in the mid Jurassic (Radwanska and Poirot, 2010) and the lone fossil siphonostomatoid is

428 from $\sim 125$ mya ago in the mid Cretaceous (Cressey and Paterson, 1973; Cressey and Boxshall,

429 1989). Both of these fossils are of rather derived members of their respective groups, which

430 suggests the transitions to parasitism in these clades occurred much earlier. The transition to

431 parasitism in the clade comprising the Notodelphyidae, Ascidicolidae and related families of

432 tunicate parasites also lead to a large diversification resulting in 699 species (Walter and 
433 Boxshall, 2021). One parasitic transition encompassing the Lernaeidae + Ozmanidae appears to

434 have occurred in freshwater and resulted in moderate species richness (129 species), perhaps as a

435 specific response to colonizing freshwater (Ho, 1994; Walter and Boxshall, 2021). Given the

436 diversity of freshwater fishes available to serve as hosts for the lernaeids, it is perhaps surprising

437 there is not greater diversity in freshwater fish parasitizing copepods when compared to those

438 parasitizing marine fishes. This could be because lernaeids are often less host specific and may

439 have speciated less as a result, or perhaps the transition to fish parasitism in freshwater by

440 lernaeids is recent.

441 While the species richness is high for some parasitic copepod clades, most transitions to

442 parasitism in copepods have not led to large radiations in terms of species number (Table 3 ). In

443 the cyclopoids, the remaining two transitions are small: there are only five known species in the

444 Thaumotopsyllidae and Eucylops bathanalicola is the only known parasite in its genus. All

445 parasitic harpacticoids are relatively species-poor incursions into parasitism. In the Ameiridae,

446 there are perhaps four or more parasitic species including Nitokra bdelluare, N. spinipes and the

447 monotypic Abscondicola and Antillesia. There are three described species of Balaenophilus (only

448 two of which were considered valid by Huys [2016]). Within the Canuellidae, the single species

449 of Echinosunaristes has the greatest evidence of parasitism, and perhaps the single species of

450 Intersunaristes and the four species of Sunaristes may be parasites or commensals. There are 14

451 obvious parasites in the Cholidyinae. In the Laophontidae, four species are likely parasitic: two

452 each of Mictyricola Nicholls, 1957 and Robustunguis Fiers, 1992. In the Peltidiidae, we consider

453 the two species of Alteuthellopsis parasites plus perhaps a few other peltidiids. A number of

454 copepods in the Tegastidae are associated with hosts, but we find available data of parasitism

455 convincing for only $A$. cnidicus. In the Thalestridae, there are four species of herbivorous 
456 copepods on brown and red algae (Huys, 2016), and we consider at least the gall-inducing

457 species parasites. Collectively, these 10 small transitions into parasitism encompass only 38

458 species. It is interesting to speculate if the low diversity in the harpacticoid parasitic clades is

459 related to their more loose associations with hosts. Many harpacticoids are epibenthic predators

460 or scavengers and these clades may represent more recent forays into parasitism.

461 There are no known parasitic species in the Calanoida, Gelyelloida, Misophrioida,

462 Mormonilloida, and Platycopioida. While this is not so conspicuous in the latter 4 orders since

463 they contain only 2-37 species each (Walter and Boxshall, 2021), the lack of parasitism in the

464 large order Calanoida is striking (Table 2). This order contains 2,709 mostly marine species, the

465 overwhelming majority of which are planktonic (Boxshall and Defaye, 2008; Walter and

466 Boxshall, 2021). There are a few isolated reports of possible symbiotic relationships among the

467 calanoids. Humes \& Smith (1974) reported that Ridgewayia fosshageni Humes \& Smith, 1974

468 formed aggregations in the vicinity of the actiniarian Bartholomea annulata (LeSueur, 1817).

469 Although these aggregations were more stable than similar aggregations formed near rocks or

470 near another actiniarian species, the copepods moved constantly and were never observed

471 coming to rest either on the anemone or on the substrate. The nature of this association is

472 uncertain. It might possibly involve the copepod feeding on mucus produced by the actiniarian

473 since another calanoid, Acartia negligens Dana, 1849 has been demonstrated capable of feeding

474 on mucus produced by reef corals; Richman et al. (1975) found that A. negligens can assimilate

475 up to half of the organic matter present in the mucus. Still, these are rare exceptions: most

476 calanoids inhabit the water column and have dual purpose mouthparts adapted for both

477 swimming and food capture (Svetlichny and Hubareva, 2005; Svetlichny et al., 2020). In fact,

478 members of the Misophrioida, Mormonilloida, and Platycopioida also exhibit mouthparts with 
479 this dual function (Sars, 1903; Boxshall, 1985). In contrast, the remaining copepod orders do not

480 use oral appendages for swimming. Indeed, the mouthparts of parasitic copepods have lost the

481 parts of the limb responsible for generating water flow. It may be that the locomotory function of

482 mouthparts in calanoids (and also misophrioids, mormonilloids, and platycopioids) has

483 constrained their morphology and made the transition to parasitism more challenging.

484 The 14 independent transitions to parasitism identified here are only a preliminary

485 estimate of parasite evolution in copepods. With only 365 of the 14,485 species of copepods

486 sampled in molecular phylogenetic analyses, most of the copepod tree remains unresolved. We

487 suspect 14 transitions to parasitism is, if anything, an underestimate. The total number of

488 transitions has been counted conservatively here (e.g., all poecilostomes counted as one

489 transition, parasitic ameirids as one transition, notodelphyids and ascidicolids as one transition,

490 etc.). While it is possible that denser phylogenetic sampling will show some of the 14 parasitic

491 clades recovered here merge into fewer clades, it is also likely that additional independent clades

492 of parasitism will be recovered considering that only 92 of the $>5,000$ parasitic copepod species

493 have been sampled. Nonetheless, the 14 transitions to parasitism identified here are substantially

494 more than previously published estimates.

495

Weinstein and Kuris (2016) recently estimated six independent transitions to parasitism

496 in the Copepoda. The difference between our counts can be attributed to a more poorly resolved

497 copepod phylogeny when Weinstein and Kuris (2016) made their estimate, different

498 interpretations of parasitism versus commensalism, or the fact that Weinstein and Kuris (2016)

499 may have been unaware of a number of the less species rich clades of parasitic copepods. We

500 agree with five of the six transitions tallied by Weinstein and Kurris (2016): (1) Balaenophilus,

501 (2) Cholidyinae, (3) Echinosunaristes, (4) the parasitic cyclopoids, and (5) the 
502 Siphonostomatoida and Monstrilloida. As a result of the increased resolution of the cyclopoid

503 phylogeny by Khodami et al. (2019), it is now clear there are at least five clades of parasitic

504 cyclopoids while Weinstein and Kuris (2016) counted only two. Strangely, one of the two they

505 counted was the enterognathid genus Zanclopus Calman, 1908; however, phylogenetic data are

506 lacking for this family and it has long been treated as a close relative of a cluster of other mostly-

507 tunicate associated families (including the Ascidicolidae, Buproridae, Botryllophilidae, and

508 Enteropsidae), so we conservatively counted this as a single transition along with the

509 Notodelphyidae and Archinotodelphyidae. It would be interesting to sample these lineages in

510 future phylogenetic studies to test if they represent one or more independent clades. Weinstein

511 and Kuris (2016) discounted the Thalestridae as loosely associated and not parasitic, but we find

512 the gall-inducing activity of some thalestrids convincing evidence of a parasitic relationship

513 (e.g., Fahrenbach, 1962; Ho and Hong 1988). Finally, Weinstein and Kuris (2016) were either

514 unaware of some of the less species-rich transitions to parasitism or did not consider the

515 following taxa parasitic: Aglaogastes cnidicus (Tegastidae), Alteuthellopsis (Peltiidae),

516 Ameiridae, Canuellidae, and Eucylops bathanalicola.

517 The notion that copepods have evolved to be parasitic at least 14 times has important

518 implications for our understanding of the evolution of the group. There are many morphological

519 changes often associated with transitions to parasitism in copepods, such as the reduction in body

520 and limb setation and segmentation; dorsoventral flattening; incorporation of additional leg

521 bearing segments into the cephalosome; cephalothorax forming a suction cup for attachment;

522 modification of antennae and maxillipeds into robustly clawed appendages; development of root-

523 like absorptive processes; and even the loss of all appendages and external segmentation. It is

524 clear these have happened convergently many times. Similarly, host seeking behaviors and 
525 strategies to avoid detection by the host have also evolved multiple times, perhaps even

526 immunomodulation. These replicate transitions to parasitism make copepods an ideal system to

527 explore morphological evolution and genetic changes associated with the evolution of a parasitic

528 lifestyle.

529 In a number of instances, clades of parasitic taxa are closely allied with taxa more loosely

530 associated with hosts. This is true of a number of poecilostome clades, the tunicate-associated

531 parasitic cyclopoids (i.e., Notodelphyidae + related families), and the parasitic harpacticoid

532 clades. Even among the Siphonostomatoida, which is generally regarded as entirely parasitic, a

533 number of taxa retain more free-living copepod morphology, and some of these appear to have

534 looser associations with hosts, such as the hydrothermal vent associated Dirivultidae Humes and

535 Dojiri, 1981 (see Tsurumi et al., 2003) and Ecbathyrion Humes, 1987, as well as some

536 asterocherids. In the context of more robust taxon sampling, it would be interesting to explore

537 the phylogeny at the bases of these clades, and to examine host associations of these groups with

538 ancestral state reconstruction analyses to infer potential avenues of host colonization.

539 What remains a major challenge to improving our understanding of parasitic copepod

540 evolution is elucidating the nature of the association symbiotic copepods have with their

541 invertebrate hosts, where little is known regarding the nature of their association (i.e., whether

542 dependent or facultative, whether commensal or parasitic) (Humes, 1987; Ho, 2001; Boxshall

543 and Halsey, 2004; Huys, 2016). Collectively there are over 2,000 species of copepods associated

544 with invertebrate hosts of which we have almost no information on the nature of their

545 association. It is common for the only host association data to be just that: an association (e.g.,

546 copepods collected in the tube of a polychaete; copepods collected from the washings of a stony

547 coral). In many cases, modified morphology is a practical indicator of parasitism, such as 
548 sucking or scraping mouthparts, or robust clawed appendages for attachment, but this is far from

549 a perfect approximation, especially for the relatively unmodified copepods associated with

550 invertebrates. Careful observation, analysis of gut contents, isotope analysis, and perhaps

551 metabolic or biochemical profiling are needed to inform our understanding of the relationship

552 symbiotic copepods have with their hosts. The nature of the relationship these more loosely

553 associated copepods have with their hosts is key to understanding the evolution of parasitism

554 since these are possible intermediate stages in the transition from free-living to parasitic. Both a

555 more thorough understanding of host associations and more robust taxon sampling in

556 phylogenetic studies are needed to improve our understanding of parasitic evolution in copepods.

\section{Conclusions}

The number of transitions to parasitism, the morphological diversity, and the host range

560 of copepods makes this group an ideal system to explore the evolution of parasitism. With 14

561 independent transitions to parasitism, copepods have the fourth greatest number of parasitic

562 origins in the Metazoa, surpassed only by the Acari (31), Hexapoda (87+), and Nematoda (18)

563 (Weinstein and Kuris, 2016). Given that 14,120 of the 14,485 copepod species have never been

564 sampled in molecular phylogenetic analyses, this study highlights the need for additional

565 sampling of copepod taxa, which may reveal additional origins of parasitism. The Cyclopoida,

566 Harpacticoida, and Siphonstomatoioda require the greatest additional sampling effort (Table 2),

567 and, coincidentally, these orders contain nearly all of the parasitic copepods. While the lack of

568 phylogenetic information available has prevented copepods from achieving their full potential as

569 a powerful model system for understanding parasite evolution, the evolutionary dynamics of host

570 associations, and morphological evolution, this group is primed for the application of molecular 
571 techniques for high-level systematic revision. A robust phylogeny of the copepods will enable

572 the revision of contentious classification of copepods, bring stability to their taxonomy, and

573 enable the exploration of the exceptional morphological variation and host range of parasitic

574 copepods.

575

576 Acknowledgements

577 We thank all the researchers that produced the molecular phylogenies used in these

578 analyses and we are grateful to all the copepod taxonomists that have cumulatively produced the

579 copepod taxonomy used in the OTT, especially through the World of Copepods Database and

580 WoRMS. We also thank Christoph Noever and two anonymous reviewers whose careful

581 comments improved this manuscript.

582 
584 Adamowicz, S. J., Menu-Marque, S., Halse, S. A., Topan, J. C., Zemlak, T. S., Hebert, P. D., \&

585 Witt, J. D. (2010). The evolutionary diversification of the Centropagidae (Crustacea,

586 Calanoida): A history of habitat shifts. Molecular Phylogenetics and Evolution 55(2): 418$587 \quad 430$.

588

Adamowicz, S. J., Menu-Marque, S., Hebert, P. D., \& Purvis, A. (2007). Molecular systematics and patterns of morphological evolution in the Centropagidae (Copepoda: Calanoida) of Argentina. Biological Journal of the Linnean Society 90(2): 279-292.

Badillo, F. J., Puig, L., Montero, F. E., Raga, J. A., \& Aznar, F. J. (2007). Diet of Balaenophilus spp. (Copepoda: Harpacticoida): Feeding on keratin at sea? Marine Biology 151(2): 751758.

Bininda-Emonds, O. R. (2004). Trees versus characters and the supertree/supermatrix" paradox". Systematic Biology 53(2): 356-359.

Blanco-Bercial, L., Bradford-Grieve, J., \& Bucklin, A. (2011). Molecular phylogeny of the calanoida (crustacea: Copepoda). Molecular Phylogenetics and Evolution 59(1): 103-113.

Boxshall, G. A. (1985). The comparative anatomy of two copepods, a predatory calanoid and a particle-feeding mormonilloid. Philosophical Transactions of the Royal Society of London, B 311(1150): 303-377.

Boxshall, G. A. \& Defaye, D. (2008). Global diversity of copepods (Crustacea: Copepoda) in freshwater. Hydrobiologia 595: 195-207. https://doi.org/10.1007/s10750-007-9014-4

Boxshall, G. A., \& Halsey, S. H. (2004). An introduction to copepod diversity. The Ray Society, London. 966 p. 
605 Bradford-Grieve, J. M., Boxshall, G. A., \& Blanco-Bercial, L. (2014). Revision of basal calanoid 606 copepod families, with a description of a new species and genus of 607 Pseudocyclopidae. Zoological Journal of the Linnean Society 171(3): 507-533.

608 Braga, E., Zardoya, R., Meyer, A., \& Yen, J. (1999). Mitochondrial and nuclear rRNA based 609 copepod phylogeny with emphasis on the Euchaetidae (Calanoida). Marine Biology 133(1), $610 \quad 79-90$.

611 Bucklin, A., Frost, B., Bradford-Grieve, J., Allen, L., \& Copley, N. (2003). Molecular systematic 612 and phylogenetic assessment of 34 calanoid copepod species of the Calanidae and 613 Clausocalanidae. Marine Biology 142(2): 333-343.

614 Clark, K., Karsch-Mizrachi, I., Lipman, D. J., Ostell, J., Sayers, E. W. (2016). GenBank. Nucleic 615 Acids Res. 44(D1): D67-72.

616 Cornils, A., \& Blanco-Bercial, L. (2013). Phylogeny of the Paracalanidae Giesbrecht, 1888 617 (Crustacea: Copepoda: Calanoida). Molecular Phylogenetics and Evolution 69(3): 861-872. 618 Cruickshank, R. H., \& Paterson, A. M. (2006). The great escape: Do parasites break Dollo's 619 law? Trends in Parasitology 22(11): 509-515.

620 Ewers-Saucedo, C., Owen, C. L., Pérez-Losada, M., Høeg, J. T., Glenner, H., Chan, B. K., \& 621 Crandall, K. A. (2019). Towards a barnacle tree of life: Integrating diverse phylogenetic 622 efforts into a comprehensive hypothesis of thecostracan evolution. PeerJ 7:e7387. 623 Eyun, S. (2017). Phylogenomic analysis of Copepoda (Arthropoda, Crustacea) reveals 624 unexpected similarities with earlier proposed morphological phylogenies. BMC $625 \quad$ Evolutionary Biology 17(1): 23.

626 Fahrenbach, W. (1962). The biology of a harpacticoid copepod. La Cellule 62: 303-376. 
627 Futuyma, D. J., \& Moreno, G. (1988). The evolution of ecological specialization. Annual Review 628 of Ecology and Systematics 19(1): 207-233.

629 Gasca, R., Suárez-Morales, E. \& Haddock, S.H.D. (2007). Symbiotic associations between 630 crustaceans and gelatinous zooplankton in deep and surface waters off California. Marine 631 Biology 151(1): 233-242. https://doi.org/10.1007/s00227-006-0478-y

632 GenBank [Internet]. Bethesda (MD): National Library of Medicine (US), National Center for 633 Biotechnology Information; [1982] - [cited 2021 Jul., 08]. Available from: 634 https://www.ncbi.nlm.nih.gov/nucleotide/ Accessed 8 May 2021.

635 Goldberg, E. E., \& Igić, B. (2008). On phylogenetic tests of irreversible evolution. Evolution: 636 International Journal of Organic Evolution 62(11): 2727-2741.

637 Heron, A. C. (1973). A specialized predator-prey relationship between the copepod Sapphirina 638 angusta and the pelagic tunicate Thalia democratica. Journal of the Marine Biological 639 Association of the United Kingdom 53(2): 429-436.

640 Heron, G. A. \& Damkaer, D. M. (1978). Seven Lubbockia species (Copepoda: Cyclopoida) from 641 the plankton of the northeast Pacific, with a review of the genus. Smithsonian Contributions 642 to Zoology 267: 1-36.

643 Hinchliff, C. E., Smith, S. A., Allman, J. F., Burleigh, J. G., Chaudhary, R., Coghill, L. M., .. . 644 Gazis, R. (2015). Synthesis of phylogeny and taxonomy into a comprehensive tree of $645 \quad$ life. Proceedings of the National Academy of Sciences 112(41): 12764-12769.

646 Hirai, J., Shimode, S., \& Tsuda, A. (2013). Evaluation of ITS2-28S as a molecular marker for 647 identification of calanoid copepods in the subtropical western north Pacific. Journal of $648 \quad$ Plankton Research 35(3): 644-656. 
649 Ho, J. (1994). Origin and evolution of the parasitic cylopoid copepods. International Journal for $650 \quad$ Parasitology 24(8): 1293-1300.

651 Ho, J. (2001). Why do symbiotic copepods matter? Hydrobiologia 453(1): 1-7.

652 Ho, J., \& Hong, J. (1988). Harpacticoid copepods (Thalestridae) infesting the cultivated wakame 653 (brown alga, Undaria pinnatifida) in Korea. Journal of Natural History, 22(6), 1623-1637.

654 Humes, A. G. \& Ho, J. S. (1969). The genus Sunaristes (Copepoda, Harpacticoida) associated

655 with hermit crabs in the western Indian Ocean. Crustaceana 17(1): 1-18.

656 Humes, A. G. \& Smith, W. L. (1974). Ridgewayia fosshageni n. sp. (Copepoda; Calanoida)

657 associated with an actiniarian in Panama, with observations on the nature of the

658 association. Caribbean Journal of Science 14(3-4): 125-139.

659 Huys, R., \& Boxshall, G. A. (1991). Copepod Evolution. The Ray Society, London. 468 p.

660 Huys, R. (1995). A new genus of Canuellidae (Copepoda, Harpacticoida) associated with

661 Atlantic bathyal sea-urchins. Zoologica Scripta 24(3): 225-243.

662 Huys, R. (2016). Harpacticoid copepods - their symbiotic associations and biogenic substrata: A 663 review. Zootaxa 4174(1): 448-729.

664 Huys, R., Fatih, F., Ohtsuka, S., \& Llewellyn-Hughes, J. (2012). Evolution of the

665 bomolochiform superfamily complex (Copepoda: Cyclopoida): New insights from ssrDNA

666 and morphology, and origin of umazuracolids from polychaete-infesting ancestors

667 rejected. International Journal for Parasitology 42(1): 71-92.

668 Huys, R., Llewllyn-Hughes, J., Olson, P. D., \& Nagasawa, K. (2006). Small subunit rDNA and 669 bayesian inference reveal Pectenophilus ornatus (Copepoda incertae sedis) as highly 670 transformed Mytilicolidae, and support assignment of Chondracanthidae and Xarifiidae to 671 Lichomolgoidea (Cyclopoida). Biological Journal of the Linnean Society 87(3): 403-425. 
672 Huys, R., Llewellyn-Hughes, J., Conroy-Dalton, S., Olson, P. D., Spinks, J. N., \& Johnston, D.

673 A. (2007). Extraordinary host switching in siphonostomatoid copepods and the demise of

674 the Monstrilloida: Integrating molecular data, ontogeny and antennulary

675 morphology. Molecular Phylogenetics and Evolution 43(2): 368-378.

676 Huys, R., Mackenzie-Dodds, J., \& Llewellyn-Hughes, J. (2009). Cancrincolidae (Copepoda,

677 Harpacticoida) associated with land crabs: A semiterrestrial leaf of the ameirid

678 tree. Molecular Phylogenetics and Evolution 51(2): 143-156.

679 Johnson, S. C., Treasurer, J. M., Bravo, S., Nagasawa, K., \& Kabata, Z. (2004). A Review of the 680 Impact of Parasitic Copepods on Marine Aquaculture. Zoological Studies 43(2): 229-243.

681 Kabata, Z. (1979). Parasitic Copepoda of British Fishes. The Ray Society, London. 468 p.

682 Khodami, S., McArthur, J. V., Blanco-Bercial, L., \& Arbizu, P. M. (2017). Molecular phylogeny

683 and revision of copepod orders (Crustacea: Copepoda). Scientific Reports 7(1): 1-11.

684 Khodami, S., Mercado-Salas, N. F., Tang, D., \& Arbizu, P. M. (2019). Molecular evidence for

685 the retention of the Thaumatopsyllidae in the order Cyclopoida (Copepoda) and

686 establishment of four suborders and two families within the Cyclopoida. Molecular

687 Phylogenetics and Evolution 138: 43-52.

688 Klimov, P. B. \& OConnor, B. (2013) Is Permanent Parasitism Reversible? - Critical Evidence

689 from Early Evolution of House Dust Mites. Systematic Biology 62(3): 411-423.

690 Krajíček, M., Fott, J., Miracle, M. R., Ventura, M., Sommaruga, R., Kirschner, P., \& Černý, M.

691 (2016). The genus cyclops (Copepoda, Cyclopoida) in Europe. Zoologica Scripta 45(6):671$692 \quad 682$. 
693 Laakmann, S., Auel, H., \& Kochzius, M. (2012). Evolution in the deep sea: Biological traits,

694 ecology and phylogenetics of pelagic copepods. Molecular Phylogenetics and

695 Evolution 65(2): 535-546.

696 Letunic, I., \& Bork, P. (2016). Interactive tree of life (iTOL) v3: An online tool for the display

697 and annotation of phylogenetic and other trees. Nucleic Acids Research 44(W1): W242-

$698 \quad$ W245.

699 Machida, R. J., Miya, M. U., Nishida, M., \& Nishida, S. (2006). Molecular phylogeny and

700 evolution of the pelagic copepod genus Neocalanus (Crustacea: Copepoda). Marine

$701 \quad$ Biology 148(5): 1071-1079.

702 Maddison, W. P. and D.R. Maddison. 2017. Mesquite: a modular system for

703 evolutionary analysis. Version $3.31 \mathrm{http}: / /$ www.mesquiteproject.org

704 Mayor, T. Y., Sheveleva, N. G., Sukhanova, L. V., Timoshkin, O. A., \& Kiril'chik, S. V. (2010).

705 Molecular-phylogenetic analysis of cyclopoids (Copepoda: Cyclopoida) from Lake Baikal

706 and its water Catchment Basin. Russian Journal of Genetics 46(11): 1373-1380.

707 McMahon, M. M. \& Sanderson, M. J. (2006). Phylogenetic Supermatrix Analysis of GenBank

708 Sequences from 2228 Papilionoid Legumes. Systematic Biology 55(5): 818-836.

709 McTavish, E. J., Hinchliff, C. E., Allman, J. F., Brown, J. W., Cranston, K. A., Holder, M. T.,

710 Rees, J. A., Smith, S. A. (2015). Phylesystem: a git-based data store for community-curated

711 phylogenetic estimates. Bioinformatics Volume 31(17): 2794-2800

712 https://doi.org/10.1093/bioinformatics/btv276

713 Minxiao, W., Song, S., Chaolun, L., \& Xin, S. (2011). Distinctive mitochondrial genome of

714 calanoid copepod Calanus sinicus with multiple large non-coding regions and reshuffled 
715 gene order: Useful molecular markers for phylogenetic and population studies. BMC

716 Genomics 12(73).

717 Oakley, T. H., Wolfe, J. M., Lindgren, A. R., \& Zaharoff, A. K. (2013). Phylotranscriptomics to

718 bring the understudied into the fold: Monophyletic Ostracoda, fossil placement, and

719 pancrustacean phylogeny. Molecular Biology and Evolution 30(1): 215-233.

720 Ogawa, K., Matsuzaki, K., \& Misaki, H. (1997). A new species of Balaenophilus (Copepoda:

721 Harpacticoida), an ectoparasite of a sea turtle in Japan. Zoological Science 14(4): 691-700.

722 Owen, C. L., Bracken-Grissom, H., Stern, D., \& Crandall, K. A. (2015). A synthetic phylogeny

723 of freshwater crayfish: Insights for conservation. Philosophical Transactions of the Royal

724 Society B: Biological Sciences 370(1662): 20140009.

725 Redelings, B. D., \& Holder, M. T. (2017). A supertree pipeline for summarizing phylogenetic

726 and taxonomic information for millions of species. PeerJ 5:e3058.

727 Rees, J. A., \& Cranston, K. (2017). Automated assembly of a reference taxonomy for

728 phylogenetic data synthesis. Biodiversity Data Journal 5:e12581.

729 Richman, S., Loya, Y. \& Slobodkin, L.R. (1975). The rate of mucus production by corals and its

730 assimilation by the reef copepod Acartia negligens. Limnology and Oceanography 20(6):

$731 \quad 918-923$.

732 Sars, G.O. (1903). Copepoda Harpacticoida Parts I \& II, Misophriidae, Longipediidae,

733 Cerviniidae, Ectinosomidae. An Account of the Crustacea of Norway, with short

734 descriptions and figures of all the species. Bergen Museum 5:1-28.

735 Shimono, T., Iwasaki, N., \& Kawai, H. (2007). A new species of Dactylopusioides (Copepoda:

736 Harpacticoida: Thalestridae) infesting brown algae, and its life history. Zootaxa 1582(1):

$737 \quad 59-68$. 
738 Svetlichny, L. S. \& Hubareva, E. S. (2005). The energetics of Calanus euxinus: locomotion,

739 filtration of food and specific dynamic action. Journal of Plankton Research 27(7): 671-682.

740 Svetlichny, L., Larsen, P. S., \& Kiørboe, T. (2020). Kinematic and Dynamic Scaling of Copepod

$741 \quad$ Swimming. Fluids (5)68: 28p. https://doi.org/10.3390/fluids5020068

742

743 Swofford, D. L. (2003). PAUP* v4.0 b10. Phylogenetic Analysis using Parsimony and Other

744 Methods.Sunderland, MA: Sinauer Associates, Sunderland.

745 Takenaka, Y., Yamaguchi, A., Tsuruoka, N., Torimura, M., Gojobori, T., \& Shigeri, Y. (2012).

746 Evolution of bioluminescence in marine planktonic copepods. Molecular Biology and

747 Evolution 29(6): 1669-1681. doi:10.1093/molbev/mss009

748 Taniguchi, M., Kanehisa, T., Sawabe, T., Christen, R., \& Ikeda, T. (2004). Molecular phylogeny

749 of Neocalanus copepods in the subarctic Pacific Ocean, with notes on non-geographical

750 genetic variations for Neocalanus cristatus. Journal of Plankton Research 26(10): 1249-

$751 \quad 1255$

752 Tsurumi, M., De Graaf, R. C., \& Tunnicliffe, V. (2003). Distributional and biological aspects of

753

754

755

756

757

758

759

760 copepods at hydrothermal vents on the Juan de Fuca Ridge, north-east Pacific Ocean. Journal of the Marine Biological Association of the United Kingdom 83(3): 469-477.

Walter, T. C., \& Boxshall, G. (2021). World of copepods database. Accessed at http://www.marinespecies.org/copepoda on 2021-5-5. doi:10.14284/356

Weinstein, S. B., \& Kuris, A. M. (2016). Independent origins of parasitism in Animalia. Biology Letters 12(7): 20160324.

Willen, E. (2000) Phylogeny of the Thalestridimorpha Lang, 1944 (Crustacea, Copepoda). Cuvilier Verlag, Göttingen, 233 p.

PeerJ reviewing PDF | (2021:06:61911:1:0:NEW 16 Jul 2021) 
762 Wu, S., Xiong, J., \& Yu, Y. (2016). Taxonomic Resolutions Based on 18S rRNA Genes: A Case

763 Study of Subclass Copepoda. PLOS ONE 10(6): e0131498. 10.1371/journal.pone.0131498

764 Wyngaard, G. A., Hołyńska, M., \& Schulte, J. A. (2010). Phylogeny of the freshwater copepod

765 Mesocyclops (Crustacea: Cyclopidae) based on combined molecular and morphological

766 data, with notes on biogeography. Molecular Phylogenetics and Evolution 55(3): 753-764.

767 Zagoskin, M. V., Lazareva, V. I., Grishanin, A. K., \& Mukha, D. V. (2014). Phylogenetic

768 information content of Copepoda ribosomal DNA repeat units: ITS1 and ITS2

769 impact. BioMed Research International 2014: 926342 1-15.

770 Zwerner, D. E. (1967). Neoscutellidium yeatmani n. sp. (Copepoda: Harpacticoida) from the

771 Antarctic fish Rhigophila dearborni Dewitt, 1962. Transactions of the American

$772 \quad$ Microscopical Society 86(2): 152-157. 


\section{Figure 1}

Figure 1. Photographs showing diversity of parasitic copepod body plans.

A. Caligidae B. Dichelesthiidae C. Pennellidae D. Lernaeopodidae E. Philichthyidae. Photos courtesy of the Natural History Museum, London.

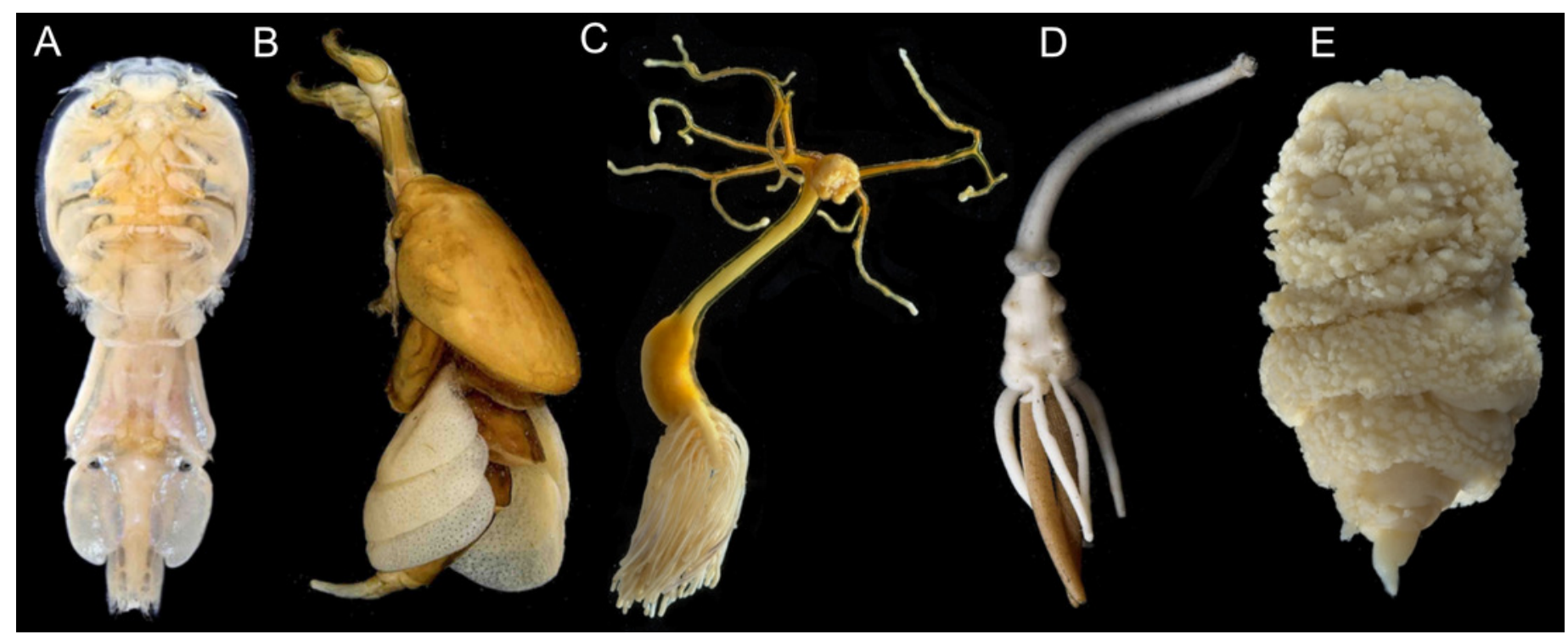




\section{Figure 2}

Figure 2. Copepod synthesis grafted tree without taxonomic data.

Phylogeny of 365 copepod taxa from 31 published phylogenies. Copepod orders are colored. Parasitic taxa are shown with red branches. Dotted red branches indicate taxa that contain free-living and parasitic species, but for which parasitic species have not yet been sampled. Bold black branches in the poecilostome clade indicate two reversals from free-living to parasitic identified in ancestral state reconstruction analyses. Red arrowheads indicate additional transitions to parasitism in constrained ancestral state reconstruction analysis not allowing reversals from parasitic to free-living. 


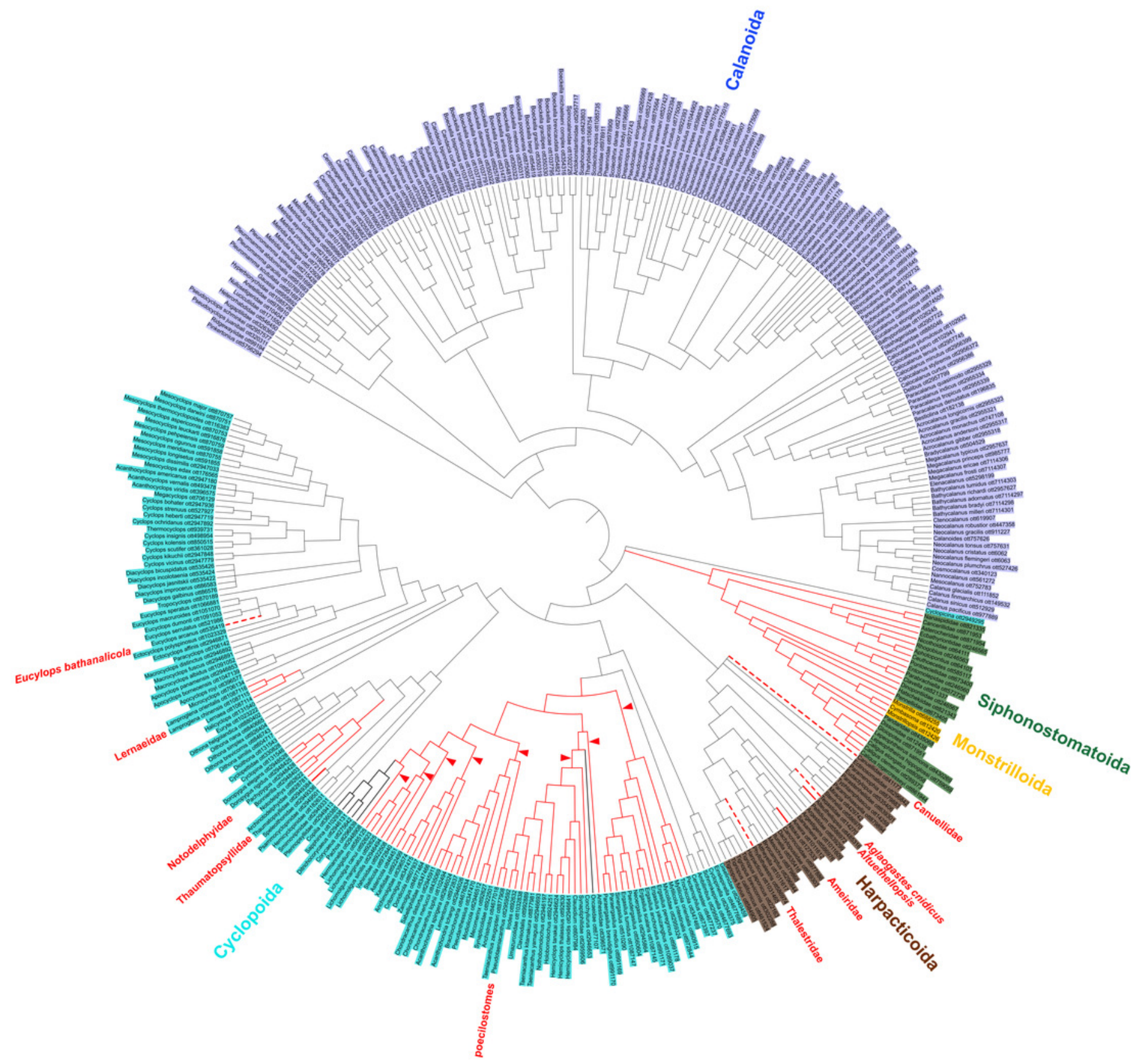




\section{Figure 3}

Figure 3. Synthesis tree of all copepod species.

Phylogeny of all copepod species including 31 published phylogenies and grafted taxonomic hierarchy. Copepod orders are colored and parasitic taxa $(n=14)$ are labeled and shown with red branches. Due to the size of the tree, clades with 200-500 tips are collapsed. 


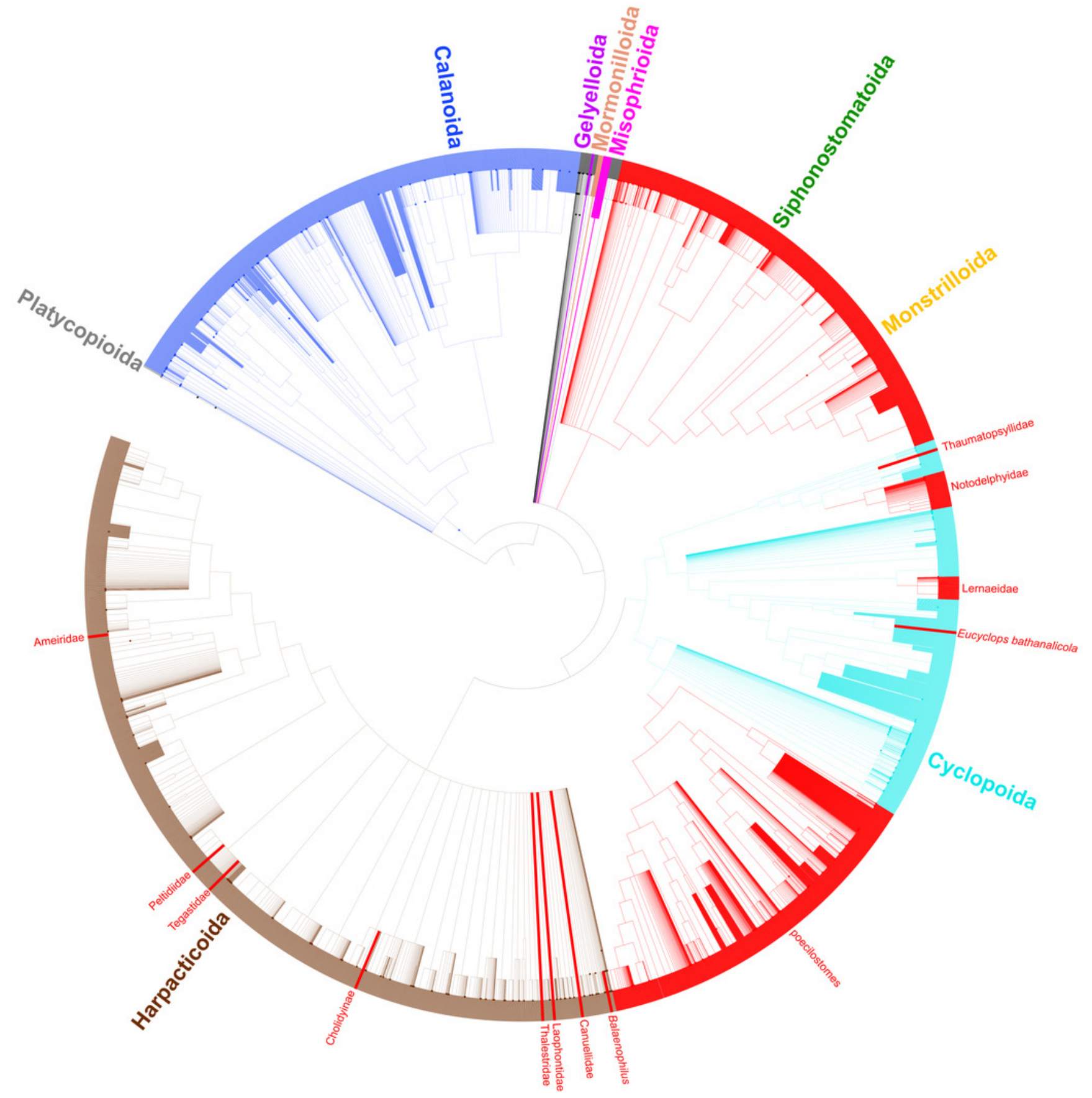


Table $\mathbf{1}$ (on next page)

Table 1. Studies used for copepod synthesis tree. 
Table 1. Studies used for copepod synthetic tree

\begin{tabular}{|c|c|c|c|c|c|c|}
\hline Rank & Study & Figure & Focal taxon & Markers & \# IG taxa & Tree method \\
\hline 1 & Khodami et al. (2019) & Figure 2 & Cyclopoida & $18 \mathrm{~S}, 28 \mathrm{~S}, \mathrm{CO} 1$ & 121 & BI, ML \\
\hline 2 & Bradford-Grieve et al. (2017) & Figure 113 & Megacalanidae & $\begin{array}{l}\text { 18S, 28S, 5.8S, CO1, } \\
\text { H3, ITS1, ITS2 }\end{array}$ & 11 & $\mathrm{BI}, \mathrm{ML}, \mathrm{MP}, \mathrm{NJ}$ \\
\hline 3 & Cornis \& Blanco-Bercial (2013) & Figure 3 & Paracalanidae & $18 \mathrm{~S}, \mathrm{CO} 1, \mathrm{H} 3$ & 22 & BI, ML \\
\hline 4 & Bradford-Grieve et al. (2014) & Figure 12 & Calanoida & 18S, 28S, CO1, CytB & 38 & BI, ML \\
\hline 5 & Blanco-Bercial et al. (2011) & Figure 2 & Calanoida & 18S, 28S, CO1, CytB & 32 & BI, ML \\
\hline 6 & Wyngaard et al. (2010) & Figure 2 & Mesocyclops & $18 \mathrm{~S}, \mathrm{ITS} 2$ & 10 & ML \\
\hline 7 & Huys et al. (2012) & Figure 2 & Cyclopoida & $18 \mathrm{~S}$ & 41 & BI, MP \\
\hline 8 & Huys et al. (2007) & Figure 1 & Copepoda & $18 \mathrm{~S}$ & 49 & BI, MP \\
\hline 9 & Huys et al. (2009) & Figure 1 & Harpacticoida & $18 \mathrm{~S}$ & 31 & BI, MP \\
\hline 10 & Lozano-Fernandez et al. (2019) & Figure 2 & Pancrustacea & 244 orthologs & 9 & $\mathrm{BI}$ \\
\hline 11 & Oakley et al. (2012) & Figure 12 & Pancrustacea & transcriptomes & 7 & BI, ML \\
\hline 12 & Eyun (2017) & Figure 3 & Copepoda & 24 nuclear genes & 9 & BI, ML \\
\hline 13 & Huys et al. (2006) & Figure 1 & Copepoda & $18 \mathrm{~S}$ & 47 & BI, MP \\
\hline 14 & Krajicek et al. (2016) & Figure 2 & Cyclops & $\begin{array}{l}12 \mathrm{~S}, 16 \mathrm{~S}, 18 \mathrm{~S}, \mathrm{CO} 1 \text {, } \\
\text { CytB, ITS } 1\end{array}$ & 15 & ML \\
\hline 15 & Minxiao et al. (2011) & Figure 9 & Copepoda & mt genome & 6 & BI \\
\hline 16 & Laakmann et al. (2012) & Figure $2 \mathrm{a}$ & $\begin{array}{l}\text { Aetideidae, } \\
\text { Euchaetidae }\end{array}$ & 18S, 28S, CO1, ITS2 & 14 & ML \\
\hline 17 & Zagoskin et al. (2014) & Figure 2 & Cyclopoida & $28 \mathrm{~S}$ & 16 & ML, ME \\
\hline 18 & Machida et al. (2006) & Figure 3 & Neocalanus & $\begin{array}{l}18 \mathrm{~S}, 28 \mathrm{~S}, \mathrm{CO} 1, \mathrm{ND} 4, \\
\text { ND6 }\end{array}$ & 7 & $\mathrm{BI}, \mathrm{ML}, \mathrm{MP}, \mathrm{NJ}$ \\
\hline 19 & Hirai et al. (2013) & Figure 3 & Calanoida & $28 \mathrm{~S}$ & 58 & BI, ML \\
\hline 20 & Takenaka et al. (2012) & Figure 3 & Copepoda & $18 \mathrm{~S}$ & 35 & ML \\
\hline 21 & Adamowicz et al. (2010) & Figure 3 & Centropagidae & $16 \mathrm{~S}$ & 25 & $\mathrm{BI}$ \\
\hline 22 & Adamowicz et al. (2007) & Figure 3 & Centropagidae & $\mathrm{CO} 1$ & 14 & $\mathrm{BI}$ \\
\hline 23 & Bucklin et al. (2003) & Figure 3 & Pseudocalanus & $18 \mathrm{~S}, \mathrm{CO} 1$ & 7 & NJ \\
\hline 24 & Bucklin et al. (2003) & Figure 2 & Neocalanus & $18 \mathrm{~S}, \mathrm{CO} 1$ & 7 & NJ \\
\hline 25 & Bucklin et al. (2003) & Figure 1 & Clausocalanus & 18S, CO1 & 14 & $\mathrm{NJ}$ \\
\hline 26 & Bucklin et al. (2003) & Figure 4 & $\begin{array}{l}\text { Calanidae, } \\
\text { Clausocalanidae }\end{array}$ & $18 \mathrm{~S}, \mathrm{CO} 1$ & 12 & $\mathrm{NJ}$ \\
\hline 27 & Taniguichi et al. (2004) & Figure 3 & Neocalanus & $16 \mathrm{~S}, 18 \mathrm{~S}$ & 11 & $\mathrm{NJ}$ \\
\hline 28 & Taniguichi et al. (2004) & Figure 2 & Calanoida & $16 \mathrm{~S}, 18 \mathrm{~S}$ & 19 & NJ \\
\hline 29 & Braga et al. (1999) & Figure 4 & Calanoida & $28 \mathrm{~S}$ & 11 & MP \\
\hline 30 & Braga et al. (1999) & Figure 6 & Euchitidae & $16 \mathrm{~S}$ & 8 & MP \\
\hline 31 & Mayor et al. (2010) & Figure 3 & Cyclopoida & $\mathrm{CO} 1$ & 19 & $\mathrm{NJ}$ \\
\hline
\end{tabular}


Table 2 (on next page)

Table 2. Phylogenetic sampling of the copepod orders. 
Table 2. Phylogenetic sampling of the copepod orders

\begin{tabular}{llll}
\hline Order & Number of species & Number of taxa in synthesis tree & $\%$ \\
\hline Calanoida & 2,709 & 169 & $6.2 \%$ \\
Cyclopoida & 4,500 & 141 & $3.2 \%$ \\
Gelyelloida & 2 & 0 & $0.0 \%$ \\
Harpacticoida & 4,771 & 30 & $0.6 \%$ \\
Misophrioida & 37 & 0 & $0.0 \%$ \\
Monstrilloida & 173 & 3 & $1.7 \%$ \\
Mormonilloida & 4 & 0 & $0.0 \%$ \\
Platycopioida & 11 & 0 & $0.0 \%$ \\
Siphonostomatoida & 2,262 & 23 & $1.0 \%$ \\
Total Copepoda & $14,485 *$ & 365 & $2.5 \%$
\end{tabular}

2

* Including 16 species of uncertain ordinal status

3 


\section{Table 3 (on next page)}

Table 3. Diversity of parasitic copepod clades by order 
Table 3. Diversity of parasitic copepod clades by order

\begin{tabular}{ll}
\hline Taxon & Number of parasitic species
\end{tabular}

Siphonostomatoida

Monstrilloida

\section{Cyclopoida}

poecilostomes

Notodelphyidae + Ascidicolidae + others

Lernaeidae + Ozmanidae

Thaumotopsyllidae

Eucylops bathanalicola

\section{Harpacticoida}

Ameiridae

$4+$

Balaenophilus

2-3

Canuellidae

$1+$

Cholidyinae

Laophontidae

4+

Peltidiidae

Tegastidae

$1+$

Thalestridae 